\title{
The Role of Personality Traits, Role Conflict, Work-family Conflict and Organization-based Self-esteem in Job Burnout and Job Compatibility of the Staff
}

\author{
Mehdi Gheyratmand
}

Department of Psychology, Quchan Branch, Islamic Azad University, Quchan, Iran

Mohammad Mohammadipour

Department of Psychology, Quchan Branch, Islamic Azad University, Quchan, Iran

Abolfazl Bakhshipor

Department of Psychology, Quchan Branch, Islamic Azad University, Quchan, Iran

\section{Doi:10.5901/mjss.2016.v7n4s2p251}

\section{Abstract}

\begin{abstract}
Job burnout and job compatibility are a multifactorial phenomenon that is a serious issue for many employees particularly the staff of Imam Khomeini (R.A.) Relief Committee since it can cause the incidence of many mental illnesses, psychosomatic and negative attitude towards professional activity and also reduced efficiency due to the tough task faced by the employees of this department. This study has been conducted with the aim of investigating the rate of job burnout and job compatibility and the effective factors such as personality traits, role conflict, work-family conflict, and organization-based self-esteem. The statistical population of the present research comprised all the employees of Imam Khomeini (R.A.) Relief Committee of Razavi Khorasan Province. To carry out the study, 152 individuals were selected through proportionate stratified sampling method. The tools applied in this research included Maslach Burnout Inventory (1985), Dawis and Lofquist Job Compatibility Questionnaire (2012), Costa and MacCrea Five-Factor Personality Inventory (1985), Role Conflict and Ambiguity Questionnaire of House, Eskaler and Lovanony (1983), Work-Family Conflict Questionnaire of Carlson, Kalmar and Wiliams (2000), and Pierce and Gardner Organization-Based Self-Esteem Scale (1989). The data collected using SPSS software at the level of 0.05 has been analyzed by Pearson correlation method. The correlation between role conflict, role ambiguity and job burnout has been obtained to be 0.193 ( $P>0.05)$. The correlation between work-family conflict (time, strain, behavior) and job burnout is equal to 0.231 ( $P>0.05)$. The correlation between personality traits and job burnout is $0.114(P>0.05)$. The correlation between organization-based self-esteem and job burnout has been obtained to be 0.00 . Also, the correlation between role conflict, role ambiguity and job compatibility is equal to $0.268(P>0.05)$. Further, the correlation between work-family conflict (time, strain, behavior) and job compatibility is $0.195(P>0.05)$. The correlation between personality traits and job compatibility is equal to $0.114(P>0.05)$. And finally, the correlation between organization-based self-esteem and job compatibility has been obtained to be $-0.117(P>0.05)$. According to the research findings, personality traits, role conflict, work-family conflict and organizationbased self-esteem are not a good predictor variable for job burnout and job compatibility.
\end{abstract}

Keywords: Job burnout, job compatibility, work-family conflict, organization-based self-esteem

\section{Introduction}

The most important factor in achieving the goals, progress and success of any organization is to consider the manpower of that organization. If organizations are concerned about developing human resources and achieving sustainable competitive advantage in the market, meeting the needs of employees is necessary and important (Chan \& White, 2009; cited in Ahmadnezhad et al., 2012).

Dawis and Lofquist (1984) have defined job compatibility as a dynamic and continuous process through a worker who seeks to progress and retain the compliance within the workplace (Dawis \& Lofquist, 1984; cited in Shahrabi Farahani, 2012). Job compatibility includes the description and explanation of the behaviors that lead to effective and good implementation of the task required by individuals and positive attitude towards new working role (Kiang Chi \& Yang Chi Yu; cited in Ahmadnezhad et al., 2012). Job burnout is a multi-dimensional structure and is composed of three interrelated components which include: emotional fatigue or exhaustion which is related to loss of the individual's emotional energies. The second component is depersonalization which recognizes the individual as a non-human object. 
The third component of job burnout is the feeling of low personal accomplishment (Maslach, Shafli \& Laiter, 2001; cited in Mohammadi et al., 2010). It is important to note that job burnout in employees causes negative attitude, unusual behaviors, personality destruction, mental fatigue and loss of motivation in their performance for execution of tasks (Andkazelki et al., 2013). Although the research literature raises the stressful aspects of the workplace as important predictors of job burnout and job compatibility, they affect personality traits, individual interactions and compatibility with the social, physical and intrapsychic environment (Larsen \& Buss, 2008; Duane Schultz; cited in Yahya Seyyed Mohammadi). If a person has verbal abilities and motor skills, but his character and personality do not let him become compatible with type of work, colleagues, clients, and other factors related to the workplace, he still cannot cope with his job duty appropriately. Big five factor model comprises five relatively sustainable factors of neuroticism, extraversion, openness, agreeableness, conscientiousness (Costa \& MacCrea, 1999; cited in Mohammadi et al., 2010).

Among other variables that can affect job burnout and job compatibility are role conflict and role ambiguity. Role ambiguity occurs when it is not clear what the individual's role is and what are the extents of the individual's responsibilities (Rass al-Tamaier, translated by Khajepour, 1999; cited in Aqaei et al, 2011).

Role conflict occurs when acquiescence to a set of job requirements is inconsistent with accepting another set of job requirements or completely impossible and studies show that role ambiguity and role conflict are considered among the most important factors causing job stress and reduced attachment and job satisfaction (Mehrabizadeh, Honarmand \& Talebzadeh, 2001; Arshadi \& Shokrkon, 2007; cited in Aqaei, 2011). Both employees and employers want to achieve more graceful organizational climate and regard the space of the organization as graceful when they feel they are doing something useful (Sadeqan et al., 2010). Pierce, Gardner, Cohinger and Dotham (1989) have defined organization-based self-esteem as follows: the extent to which a person believes himself as a capable, important and valuable member in the organization. Organization-based self-esteem is the self-assessment of the values and merits of an individual as a member of the organization (Pierce \& Gardner, 1989; cited in Sakhravi et al., 2013).

The interference between work and family responsibilities is under consideration as a major issue that has affected both employers and employees. Kahn (1964) and Biotel and Green House (1985) have defined work-family conflict as follows: "Some kind of interrole conflict in which the pressures arising from the roles of the scope of work and family are incompatible with each other in some respects; hence, performing a role (job and family) makes it difficult to do the other role (Barnet \& Hi, 2001; Edvard \& Ross Bard, 2000; Jakinz, Rapti \& Crater, 2000; Shain \& Chen, 2011; cited in Baghban, Iran).

Since one of the main sections of each human resources community is vulnerable to that community, we assume that role conflict, work-family conflict, personality traits and organization-based self-esteem have an impact on the staff and these variables affect job burnout and job compatibility. To this end, we have attempted in this study to answer this question as to whether personality traits, role conflict, work-family conflict and organization-based self-esteem influence job burnout and job compatibility.

\section{Research Methodology}

The present research is a correlational study and has been designed in order to identify the variables affecting job burnout and job compatibility. The statistical population of the study consists of all the employees of Imam Khomeini (R.A.) Relief Committee of Razavi Khorasan Province which amount to 720 individuals working in the summer of (2015).

\section{Sample Size and Sampling Method}

Given that the entity of Imam Khomeini Relief Committee of Razavi Khorasan Province has 28 centers across the province, proportionate stratified sampling method was applied and the sample size was calculated using Cochran formula and was estimated to be 152 individuals.

\section{Data Collection Tools}

In this study, the following measuring tools were used:

Dawis and Lofquist Job Compatibility Questionnaire: Job Compatibility Questionnaire prepared by Leila Shahrabi Farahani (2012) includes 36 questions. In the study performed by Shahrabi Farahani (2012), Job Compatibility Questionnaire along with Dunnett Satisfaction Questionnaire were simultaneously implemented on a sample of 50 people. Then, the rate of correlation between the scores of subjects in two tests was calculated. The correlation coefficient was obtained to be 0.73 which indicates the adequate and acceptable construct validity of this questionnaire. 
Cronbach alpha for Dawis and Lofquist Job Compatibility Questionnaire has been provided below: progress value:0.79; comfort value: 0.85 ; base value: 0.80 ; altruism value: 0.90 ; safety value: 0.82 ; autonomy value: 0.70 ; adjustment style: 0.76 ; all questions: 0.84 .

Maslach Burnout Inventory: Job Burnout Inventory was made in(1985) by Maslach. This tool is based on a new estimate of the phenomenon of stress or burnout. This questionnaire contains 22 questions. In order to assess the reliability of this questionnaire, Maslach and Jackson used Cronbach's alpha coefficient and reported the amount of the reliability of each subscale corresponding to the following items: Emotional exhaustion subscale: 0.92; depersonalization subscale: 0.79 and individual performance subscale: 0.71 . In the study conducted by Khaledi in(1997) in Iran, the reliability of the whole questionnaire was reported to be 0.91 .

NEO-FFI Five-Factor Inventory: NEO questionnaire was designed by Costa and MacCrea in(1985) to assess five factors of personality. This questionnaire includes 60 questions and 5 subscales. Costa and MacCrea suggest that NEOFFI shortened tool exactly matches its full form, NEO-PI, so that the scales of the short form have the correlation above 0.68 with the scales of the full version of NEO questionnaire.

Role Conflict and Ambiguity Questionnaire: This questionnaire was prepared by House, Eskaler and Lovanony in(1983). This scale contains 14 questions, 6 items of which assess role ambiguity and 8 other items measure role conflict. Abolqasemi et al. (2006) obtained Cronbach's alpha coefficient of this scale to be 0.89 . They also reported 0.71 and 0.66 respectively as the reliability coefficients of role ambiguity and role conflict.

Organization-Based Self-Esteem Scale: This questionnaire was designed by Pierce and Gardner in(1989) and was translated into Farsi for implementation. It has 10 questions on a 5-point Likert scale, from strongly disagree (1) to strongly agree (5). Pierce and Gardner (2004) reported the reliability coefficient of this test as a whole to be between 0.82 and 0.92 .

Work-Family Conflict Questionnaire: This questionnaire was drawn up by Carlson, Kalmar and Wiliams in(2000). This 18-item questionnaire was prepared to assess the severity of work-family conflict. This scale evaluates the six aspects of work-family conflict (based on: time, strain, behavior). Answers range from option one (strongly disagree) to five (strongly agree) using a Likert scale. Motesharre'ei et al. (2013) have reported the reliability coefficient of this test to be 0.91 using Cronbach's alpha and 0.924 using split-half method.

\section{Research Findings}

In this section, the research findings have been provided descriptively and in relation to the hypotheses. In Table 2-1, descriptive indicators of the research variables have been presented. Considering the indicators in Table 2-1, among the variables of personality traits, agreeableness (a) has the highest average (37.38) and neuroticism (n) has the lowest average (16.93). In the variable of work-family conflict, time-based work-family conflict (1) has the highest average (7.92) and strain-based work-family conflict (2) has the lowest average (6.3). In role conflict, the variable of role ambiguity (2) has the highest average (21.94) and role conflict has the lowest average (10.27). In organization-based self-esteem, the average is 36.41. In the variable of job compatibility, comfort value (2) has the highest average (40.10) and autonomy value (6) has the lowest average (6.43). In job burnout, the subscale of individual performance (3) has the highest average (31.67) and the subscale of emotional exhaustion (1) has the lowest average (8.87). On the other hand, the amount of skewness and kurtosis of all the variables was between +1.96 and 1.96 and we can say with $95 \%$ confidence that data distribution is almost normal.

Table 2-1: Descriptive indicators of variables

\begin{tabular}{|l|c|c|c|c|c|c|c|}
\hline Variables & Number & Average & Standard error & Standard deviation & Variance & Skewness & Kurtosis \\
\hline neuroticism & 152 & 16,9276 & .45637 & 5.62645 & 31.657 & .302 & -.866 \\
\hline Extraversion & 152 & 32,2829 & .39499 & 4.86972 & 23.714 & -.458 & -.409 \\
\hline openness & 152 & 23,8421 & .34006 & 4.19256 & 17578 & -.059 & .056 \\
\hline agreeablenss & 152 & 32,3882 & .42235 & 5,20704 & 27,113 & .182 & .225 \\
\hline conscientiousness & 152 & 37,3750 & .42684 & 5,26240 & 27,693 & -.583 & .172 \\
\hline Time-based work-family conflict & 152 & 7,9211 & .21562 & 2,65830 & 7,067 & .468 & -.408 \\
\hline Strain-based work-family conflict & 152 & 6,2961 & .15362 & 1,89401 & 3,587 & .271 & .232 \\
\hline Behavior-based work-family conflict & 152 & 6,7171 & .20986 & 2,58733 & 6,694 & .847 & .824 \\
\hline Time-based family-work conflict & 152 & 6,4211 & .15911 & 1,96164 & 3,848 & .461 & .703 \\
\hline Strain-based family-work conflict & 152 & 7,5329 & .18504 & 2,28127 & 5,204 & .306 & .683 \\
\hline
\end{tabular}




\begin{tabular}{|l|c|c|c|c|c|c|c|}
\hline Behavior-based family-work conflict & 152 & 6,8750 & .16204 & 1.99772 & 3,91 & -.088 & .664 \\
\hline Total conflict & 152 & 41,7632 & .63715 & 7,85256 & 61,705 & .053 & -.430 \\
\hline Role conflict & 152 & 10,2697 & .31198 & 3,84634 & 14,794 & 1,262 & 1,320 \\
\hline Role ambiguity & 152 & 21,9408 & .32993 & 4,06769 & 16,546 & -.399 & -.322 \\
\hline Total role & 152 & 32,2105 & .45632 & 5,62590 & 31,651 & .364 & 1,585 \\
\hline Self-esteem & 152 & 36,4079 & .47446 & 5,84590 & 34,217 & -.099 & -.230 \\
\hline Compatibility, progress value & 152 & 11,3026 & .15705 & 1,93620 & 3,749 & -.808 & 1,891 \\
\hline Compatibility, comfort value & 152 & 40,1053 & .51883 & 6,39656 & 40,916 & .326 & .958 \\
\hline Compatibility, base value & 152 & 13,1184 & .27262 & 3,36112 & 11,297 & -.342 & -.452 \\
\hline Compatibility, altruism value & 152 & 18,5822 & .21580 & 2,66059 & 7,079 & -.871 & 1,460 \\
\hline Compatibility, safety value & 152 & 16,9408 & .22832 & 2,81849 & 7,924 & -.083 & -.205 \\
\hline Compatibility, autonomy value & 152 & 6,4342 & .15100 & 1,86168 & 3,466 & -.235 & -.183 \\
\hline Compatibility, adjustment style & 152 & 8,6513 & .1829 & 2,25600 & 5,090 & .232 & .077 \\
\hline Overall compatibility & 152 & 115,1382 & 1,12970 & 13,92794 & 193,987 & -.399 & .558 \\
\hline Burnout, emotional exhaustion & 157 & 8,8790 & .64965 & 8,14008 & 66,261 & 1,291 & 1,571 \\
\hline Burnout, depersonalization & 157 & 3,9809 & .35352 & 4,42961 & 19,621 & 1,580 & 1,317 \\
\hline Burnout, individual performance & 157 & 31,6688 & .45903 & 5,75169 & 33,082 & -.134 & -.210 \\
\hline Total burnout & 157 & 44,5287 & .83834 & 10,50431 & 110,341 & .834 & 1,912 \\
\hline
\end{tabular}

To analyze the obtained data, Pearson correlation coefficient statistical test was applied. As can be seen:

Table 2-2: Correlation between predictor and criterion variables

\begin{tabular}{|l|l|c|c|}
\hline \multirow{2}{*}{ neuroticism } & Pearson correlation & Compatibility & Burnout \\
\cline { 2 - 4 } & Significance level & -.113 & .035 \\
\hline \multirow{2}{*}{ Extraversion } & Pearson correlation & .168 & .670 \\
\cline { 2 - 4 } & Significance level & .024 & -.076 \\
\hline \multirow{2}{*}{ openness } & Pearson correlation & .773 & .353 \\
\cline { 2 - 4 } & Significance level & .049 & -.028 \\
\hline \multirow{2}{*}{ agreeablenss } & Pearson correlation & .1451 & .733 \\
\cline { 2 - 4 } & Significance level & .075 & -.015 \\
\hline \multirow{2}{*}{ conscientiousnes } & Pearson correlation & .051 & .854 \\
\cline { 2 - 4 } & Significance level & .534 & .076 \\
\hline
\end{tabular}

There is no statistically significant relationship between personality traits (n-e-o-a-c) with job compatibility and job burnout since the significance level is higher than $0.05(P<0.05)$.

Table 2-3: Correlation between predictor and criterion variables

\begin{tabular}{|l|l|c|c|}
\hline \multicolumn{2}{|c|}{} & Compatibility & Burnout \\
\hline \multirow{2}{*}{ Time-based work-family conflict } & Pearson correlation & -.156 & .213 \\
\cline { 2 - 4 } & Significance level & .055 & .009 \\
\hline \multirow{3}{*}{ Strain-based work-family conflict } & Pearson correlation & -.132 & .078 \\
\cline { 2 - 4 } & Significance level & .105 & .343 \\
\hline \multirow{2}{*}{ Behavior-based work-family conflict } & Pearson correlation & -.055 & .101 \\
\cline { 2 - 4 } & Significance level & .501 & .214 \\
\hline \multirow{2}{*}{ Time-based family-work conflict } & Pearson correlation &. .031 & .027 \\
\cline { 2 - 4 } & Significance level & .703 & .745 \\
\hline \multirow{2}{*}{ Strain-based familly-work conflict } & Pearson correlation & -.033 & .031 \\
\cline { 2 - 4 } & Significance level & .685 & .702 \\
\hline \multirow{2}{*}{ Behavior-based family-work conflict } & Pearson correlation & .061 & .075 \\
\cline { 2 - 4 } & Significance level & .459 & .361 \\
\hline \multirow{2}{*}{ Total conflict } & Pearson correlation & -.136 & .159 \\
\cline { 2 - 4 } & Significance level & .096 & .051 \\
\hline
\end{tabular}


The results of Table 2-3 indicate that there is no statistically significant relationship between the subscales of work-family conflict with job compatibility and job burnout since the significance level is higher than $0.05(P<0.05)$.

Table 2-4: Correlation between predictor and criterion variables

\begin{tabular}{|l|l|c|c|}
\hline \multicolumn{2}{|c|}{} & Compatibility & Burnout \\
\hline \multirow{2}{*}{ Role conflict } & Pearson correlation & -.195 & .106 \\
\cline { 2 - 4 } & Significance level & .016 & .192 \\
\hline \multirow{2}{*}{ Role ambiguity } & Pearson correlation & -.186 & -.160 \\
\cline { 2 - 4 } & Significance level & .022 & .049 \\
\hline \multirow{2}{*}{ Total role } & Pearson correlation & -.268 & -.043 \\
\cline { 2 - 4 } & Significance level & .001 & .599 \\
\hline
\end{tabular}

According to Table 2-4, there is no statistically significant relationship between the subscales of role conflict with job compatibility and job burnout since the significance level is higher than $0.05(P<0.05)$.

Table 2-5: Correlation between predictor and criterion variables

\begin{tabular}{|l|l|c|c|}
\hline \multicolumn{2}{|c|}{} & Compatibility & Burnout \\
\hline \multirow{2}{*}{ Self-esteem } & Pearson correlation & -.117 & .000 \\
\cline { 2 - 4 } & Significance level & .153 & .999 \\
\hline
\end{tabular}

Based on Table 2-5, there is no statistically significant relationship between the scale of organization-based self-esteem with job compatibility and job burnout since the significance level is higher than $0.05(P<0.05)$.

\section{Discussion and Conclusion}

Given the obtained results, the relationship between the variables of role conflict, role ambiguity, job burnout and job compatibility is not significant and the research hypothesis is rejected. This result was not consistent with previous research since in the study conducted by Asghar Aqaei and Dariush Jalali in (2011 )entitled "Predicting role ambiguity and conflict, job burnout and creating four spillover of counselors stress in counseling centers of Esfahan based on demographic characteristics", the results showed that role conflict and role ambiguity are a good predictor of job burnout. In another study entitled "Investigating the relationship between the mental pressure resulting from role conflict and role ambiguity with performance and job satisfaction" which was carried out by Arshadi and Shokrkon (2007), it was revealed that role ambiguity and role conflict have a significant negative relationship with job compatibility and job satisfaction. The relationship between the variables of work-family conflict and job burnout is not significant and the research hypothesis is rejected. This result was inconsistent with previous studies since in the research entitled "The relationship between workfamily conflict with the components of job burnout and the desire to leave work", which was conducted by Farhadi et al. in(2014), it was found that there is a significant positive relationship between work-family conflict and job burnout. Further, Tikulita and Yuglia (2014) performed a research entitled "Examining work-family conflict and job compatibility and demonstrated that work-family conflict has a significant negative relationship with job compatibility. The relationship between the variable of personality traits (n-e-o-a-c) with job burnout and job compatibility is not significant. This result was not congruent with previous studies since in a study entitled "Investigating the relationship between job burnout and personality types" conducted by Sheikhi Sari and Esmaeilifar (2010), it was revealed that employees with high level of neuroticism have more job burnout and those employees who have obtained a higher score for extraversion show lower job burnout. In another research, Mohammadi and Mohammadniya (2010) investigated the relationship between 5 big personality factors and job burnout. The results suggested that there is a relationship between neuroticism and job burnout. For example, in a study by Molayi et al. (2014) entitled "Analyzing the relationship between 5 big personality factors and locus of control with job compatibility of Gas Company employees, it was concluded that neuroticism has a significant negative relationship with job compatibility; there is a significant positive relationship between extraversion and job compatibility and also between conscientiousness and job compatibility; and openness has no relationship with job compatibility. The relationship between organization-based self-esteem with job burnout and job compatibility is not significant and the research hypothesis is rejected. This finding is not consistent with previous studies. For instance, in a study entitled "Examining the relationship between organization-based self-esteem and job burnout" which was 
conducted by David Elvy and Patil (2013), it was found that there is a significant negative relationship between organization-based self-esteem and job burnout. Additionally, Sadeqian and Abedi (2008) carried out a study entitled "Examining the relationship between organization-based self-esteem with organizational feedback and job compatibility among the employees of Education" and demonstrated that a significant positive relationship exists between organization-based self-esteem and job compatibility. Among the factors involved in non-confirmation of the results obtained by previous researchers are lack of the subject's trust in the test conditions due to holding the test in online mode for each person, monitoring of the Province Research Affairs as a superior over the subjects' performance and the ability to identify the subjects' codes for this position, the research work being beyond the subject's patience due to the large number of questions and psychological exploration of the subjects. The mentioned instances caused the subjects to engage in little self-disclosure with a kind of fear and caution. Unfortunately, this affected the research results.

\section{References}

Ahmadnezhad, M., Sepehrian, A. \& Shojaei, Kh. (2012). Investigating the relationship between emotional intelligence and the quality of working life with compatibility among tuition official teachers of primary school in Sardasht city in the academic year( 2010-11). Research in Curriculum.

Ahmadnezhad, M., Hasani, M., Sepehrian, A. \& Shojaei, F. (2012). Examining the relationship between emotional intelligence and the quality of working life with job compatibility among tuition and official teachers of primary school in Sardasht city in the academic year(2010-11). Journal of Research in Curriculum, 9 (1): 123-136.

Aqaei, A., Jalali, D., Hasanzadeh, R. \& Aslan, Z. (2011). Predicting role ambiguity and conflict, job burnout and creating four spillover of counselors stress in counseling centers of Esfahan based on their demographic characteristics. New Findings in Psychology, 5 (20).

Andkazelki, M., Sarvqad, S. \& Barzgar, M. (2013). The relationship between dimensions of organizational justice with job burnout, role ambiguity and role conflict among the staff. Social-psychological journal, 8 (28).

Baghban, I., Malekiha. M. \& Fatehizadeh, M. (2009). Studying the effectiveness of the management of work - family conflict in reducing work - family conflict among working women.

David E , Gonzaga University (2013), Exploring the Relationship Between Organization- Based self Esteem and Burnout: A Preliminary Analysis.

Kanning U, Hill A, (2012) organization-based self- esteem scale-adaptation in an international context.

Katja K, tekavae M, (2014), work-family conflict : A Review of an tecedents and autocomes.

Sheikhi Sari, H. \& Esmaeilifar, N. (2010). The relationship between job burnout and five factor personality types among the staff of Tehran Municipality. Journal of new findings in industrial / organizational psychology, 1 (4).

Shokrkon, H. \& Arshadi, N. (2007). Investigating the relationship between the mental pressure resulting from role conflict and role ambiguity with performance and job satisfaction with regard to the moderating effects of job autonomy and group cohesion among the staff of National Company of oil-rich regions in the south of Ahvaz. Journal of Education and Psychology, Ahvaz University of Shahid Chamran.

Sakhravi, R., Zahiri, A., Ahmadi Chegini, S. \& Karamirad, B. (2013). Studying the relationship between organization-based self-esteem and organizational justice with regard to the mediating role of perceived support in the staff. Social-psychological journal, 8 (29).

Schultz, D. \& Schultz, S. (2005). Theories of Personality. Translated by Seyyed Mohammadi (2010). Virayesh Publishing.

Sadeqian, F. \& Abedi, M. (2009). Examining the relationship between organization-based self-esteem with organizational feedback and job compatibility and personality types. Journal of educational and psychological research, 4. Esfahan University.

Shahrabi Farahani, L. (2012). Investigating the concept and components of Dawis and Lofquist Job compatibility theory and making a tool for measuring Han among the female teachers of District 15 of Tehran in the academic year 2010-11. Journal of Occupational and Organizational Consulting.

Farhadi, A., Movahhedi, Y., Na'lchi, M., Darayi, M. \& Mohammadzadegan, R. (2013). The relationship between work-family conflict with the components of job burnout and the desire to leave work among female nurses. Iran Journal of Nursing, 26 (83).

Kakabaraei, K. \& Afsharniya, K. (2012). Short version of the list of Big Five Factors: Factor non-interpretability test in parents of normal and exceptional children.

Mohammadi, Sh. \& Mahmoudniya, A. (2010). The relationship between five personality traits and job burnout among counselors. Journal of Occupational and Organizational Consulting, 2 (4).

Molayi, A., Yazdanbakhsh, K. \& Karami, J. (2014). The relationship between big five factors of personality and locus of control with job compatibility of Gas Company employees of Kermanshah. Journal of Personality and Individual Differences

Nicoleta M, Buliga D, 2014, work- family Conflict and patisfaction. The media Role of congnitions. 